Article

\title{
Serrated Flow Behavior of Hot-Rolled Fe-6.5wt.\%Si Sheet with Layered Structure
}

\author{
Xiangju Shi ${ }^{1}$, Yongfeng Liang ${ }^{1} \oplus$, Binbin Liu ${ }^{1}$, Zhiyi Ding ${ }^{2}$, Bao Zhang ${ }^{1}$ and Feng Ye ${ }^{1, *}$ \\ 1 State Key Laboratory for Advanced Metals and Materials, University of Science and Technology Beijing, \\ Beijing 100083, China; shixiangjuluck@163.com (X.S.); liangyf@skl.ustb.edu.cn (Y.L.); \\ bbliu@ustb.edu.cn (B.L.); b20160411@xs.ustb.edu.cn (B.Z.) \\ 2 Department of Mechanical Engineering, The Hong Kong Polytechnic University, Hong Kong 999077, China; \\ zhiyi.ding@polyu.edu.hk \\ * Correspondence: yefeng@skl.ustb.edu.cn; Tel.: +86-10-6233-3899
}

Received: 19 August 2019; Accepted: 18 September 2019; Published: 20 September 2019

check for updates

\begin{abstract}
The microstructures and mechanical properties of the hot-rolled Fe-6.5wt.\%Si sheet are analyzed. The microstructure of the hot-rolled sheet is layered along the thickness direction. The surface exhibits fine and equiaxed grains, whereas the center part shows coarse and elongated grains with $a<101>$ fiber texture along the rolling direction. Serrated flow behavior is observed during tensile deformation of both the hot-rolled sheet and its center samples at $350{ }^{\circ} \mathrm{C}$; thus, the serrated flow of the hot-rolled sheet is mainly attributed to the serration of the center part. The analyses of dislocation configurations, ordered structures, and crystal orientation show that the serrated flow behavior results from the interaction of solutes with mobile dislocations. Mobile dislocations are pinned by combining parallel forest dislocations with the pipe diffusion of solution atoms. This study provides a new perspective for the deformation mechanism of the Fe-6.5wt.\%Si alloy.
\end{abstract}

Keywords: Fe-6.5wt.\%Si alloy; serrated flow; forest dislocation; pipe diffusion; mobile dislocation; layered microstructure

\section{Introduction}

Fe-6.5wt.\%Si alloy exhibits excellent soft magnetic properties, such as high permeability, low coercivity, and near-zero magnetostriction, which result in favorable application of this alloy in high-frequency transformers [1,2]. However, its intrinsic brittleness and poor formability resulting from the ordered phases ( $\mathrm{B} 2$ and $\mathrm{DO}_{3}$ ordered structures) limit the fabrication of Fe-6.5wt.\%Si alloy sheets by the conventional casting-rolling process, which hinders the development and application of the alloy [3-5].

The formability of the hot-rolled sheet can be enhanced by warm deformation [6,7]. Recently, Li et al. [7] found that the warm deformation may induce work softening by the deformation-induced disordering and dynamic recovery. Liang et al. [6] fabricated the alloy sheet by hot-warm-cold rolling. Accordingly, warm deformation is significant for deformation mechanism research and preparation of the alloy.

During warm deformation, serrated flow behavior is usually accompanied by repetitive yielding and plastic instability in the stress-strain curves [8]. Some special deformation mechanisms and the structural evolution during deformation can be reflected by the serration characteristics. Therefore, the serrated flow behavior is of great theoretical value for plastic deformation, which has attracted wide attention and interest. The serrated flow behavior has been found in materials such as aluminum alloys, magnesium alloys, bulk metallic glass, transformation-induced plasticity (TRIP)-assisted steel, and China low-activation martensitic steel [8-13]. 
The Fe-6.5wt.\%Si alloy is a body centered cubic (BCC) alloy together with $\mathrm{B} 2(\mathrm{FeSi})$ or $\mathrm{D0}_{3}\left(\mathrm{Fe}_{3} \mathrm{Si}\right)$ ordered structures [14]. Recently, Honjo et al. [15-17] studied the serrated plastic flow of $\mathrm{L1}_{2}$-type ordered intermetallics, including $\mathrm{Ni}_{3}(\mathrm{Si}, \mathrm{Ti}), \mathrm{Ni}_{3} \mathrm{Al}$, and $\mathrm{Co}_{3} \mathrm{Ti}$ alloys, at intermediate temperature. The activation energy of pipe diffusion in the dislocation core is very close to the activation energy of the serrated plastic flow. However, the serrated flow behavior in the Fe-6.5wt.\%Si alloy has not been widely investigated. Fu et al. $[18,19]$ observed serrated plastic flow during warm deformation in the elongated-grained Fe-6.5wt.\%Si alloy obtained by directional solidification. They revealed that the deformation twinning is responsible for the serrated flow behavior. However, it is not clear whether the serrated flow behavior in the elongated-grained Fe- $6.5 \mathrm{wt} . \% \mathrm{Si}$ alloy fabricated by rolling occurs. The mechanisms of serrated flow in Fe-6.5wt.\%Si alloy need to be further discussed and analyzed.

In this study, the microstructures and tensile deformation behavior of hot-rolled Fe-6.5wt.\%Si alloy were investigated. Serrated flow behavior during tensile deformation was observed. The layered structure of the hot-rolled Fe-6.5wt.\%Si alloy provided sound evidence that the grain morphology, degree of order, and orientation can result in varied deformation behavior. The results are expected to provide a theoretical supplement for the serrated flow behavior and deformation mechanism of the Fe-6.5wt.\%Si alloy.

\section{Materials and Methods}

A Fe-6.5wt.\%Si alloy ingot was prepared by melting pure iron (99.5 wt.\%) and metallic silicon (99 wt.\%) in a vacuum induction furnace at medium frequency, and the vacuum degree is approximately $50 \mathrm{~Pa}$. A $200 \mathrm{~kg}$ flat ingot with a size of $600 \mathrm{~mm}$ in length, $400 \mathrm{~mm}$ in width, and $90 \mathrm{~mm}$ in thickness was cast, and the cast temperature was set at approximately $1500^{\circ} \mathrm{C}$. The ingot was then slowly cooled to reduce cracks. The chemical composition is listed in Table 1.

Table 1. Chemical composition of Fe-6.5wt.\%Si alloy (wt.\%).

\begin{tabular}{ccccccc}
\hline Si & $\mathbf{C}$ & $\mathbf{N}$ & $\mathbf{M n}$ & $\mathbf{P}$ & $\mathbf{S}$ & $\mathbf{F e}$ \\
\hline 6.47 & 0.0052 & 0.0026 & 0.019 & 0.005 & 0.0019 & Bal \\
\hline
\end{tabular}

After homogenization at $1100{ }^{\circ} \mathrm{C}$ for $5 \mathrm{~h}$, the flat ingot was directly hot rolled into sheets with a size of $2300 \mathrm{~mm}$ in length, $250 \mathrm{~mm}$ in width, and $2.5 \mathrm{~mm}$ in thickness in the temperature range of 900-1100 ${ }^{\circ} \mathrm{C}$. The reduction of each pass during hot rolling is listed in Table 2 . The samples were cut during rolling due to excessive length. After the fourth pass, the sample was reheated in the furnace.

Table 2. The reduction of each pass during hot rolling.

\begin{tabular}{cccc}
\hline Pass & Thickness $(\mathbf{m m})$ & Reduction $(\mathbf{m m})$ & Reduction Ratio $(\%)$ \\
\hline 0 & 90 & 0 & 0 \\
1 & 81 & 10 & 10.0 \\
2 & 71 & 13 & 12.3 \\
3 & 56 & 16 & 21.1 \\
4 & 36 & 20 & 35.7 \\
5 & 18 & 18 & 50.0 \\
6 & 11 & 7 & 33.3 \\
7 & 5.1 & 5.8 & 57.5 \\
8 & 2.5 & 2.6 & 51.0 \\
\hline
\end{tabular}

The microstructures and crystallographic orientation were detected by an electron backscattered diffraction (EBSD) detector in scanning electron microscopy (SEM, ZEISS SUPRA 55, Carl Zeiss, Jena, Germany). High-temperature tensile samples with a thickness of $0.5 \mathrm{~mm}$ were cut from the surface and center of the hot-rolled sheet. The sampling position corresponds to the rectangular region in Figure 1. The tensile axis of the samples was parallel to the rolling direction. Tensile properties were 
tested by DDL-50 electronic universal testing machine (DDL-50, Changchun Research Institute for Mechanical Science Co., Ltd., Changchun, China) at $350{ }^{\circ} \mathrm{C}$ and $450{ }^{\circ} \mathrm{C}$ with a strain rate of $5 \times 10^{-4} \mathrm{~s}^{-1}$. The samples were heated to the deformation temperature at an average rate of approximately $0.25^{\circ} \mathrm{C} / \mathrm{s}$, and held for $10 \mathrm{~min}$ under isothermal condition. The fracture surface was observed by SEM (ZEISS SUPRA 55, Carl Zeiss, Jena, Germany).

Dislocation configurations of the hot-rolled sheet were observed by transmission electron microscopy (TEM, JEM-2100, JEOL, Tokyo, Japan). The specimens for TEM analysis were fabricated by electrochemical polishing in a mixed solution of $6 \%$ perchloric acid and $94 \%$ ethanol at $30 \mathrm{~V}$ and $-20{ }^{\circ} \mathrm{C}$.

\section{Results}

\subsection{Grain Morphology and Orientation of the Hot-Rolled Sheet}

Figure 1 shows grain morphology and orientation of the hot-rolled sheet. A significant difference in orientations and grain morphology is visible along the thickness direction, namely, the normal direction (ND). The surface part was composed of equiaxed grains with random orientations, and the size of the equiaxed grains was approximately $30 \mu \mathrm{m}$. For the center, the elongated grains with a strong $<101>$ fiber texture along the rolling direction were obtained, and the width of the elongated grains was approximately $110 \mu \mathrm{m}$. A transition region between the surface and center part consisted of elongated grains with a $<001>$ fiber texture.

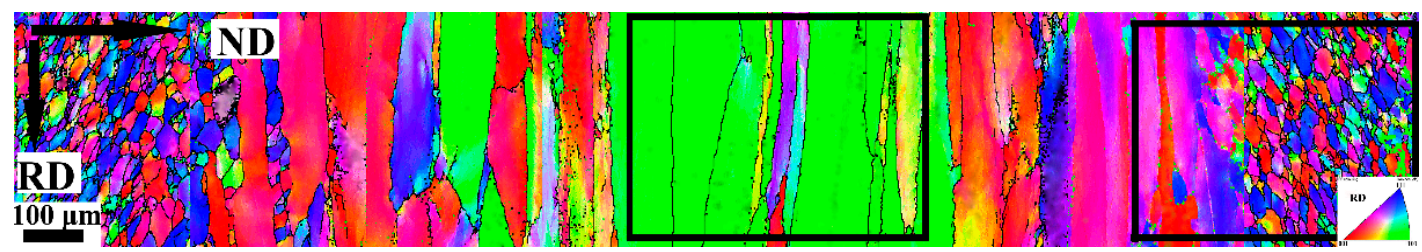

Figure 1. Orientation imaging of the hot-rolled sheet. A color-coded map referred to the rolling direction is shown on the lower right side. (RD: rolling direction; ND: normal direction of the rolled plane).

\subsection{Tensile Properties and Fracture Morphology}

Figure 2 shows the tensile curves of the hot-rolled sheet with a thickness of $2.5 \mathrm{~mm}$ at $350{ }^{\circ} \mathrm{C}$ and $450{ }^{\circ} \mathrm{C}$. Serrations appeared in the tensile curve at $350^{\circ} \mathrm{C}$ after the ultimate tensile strength, as shown in Figure 2a, whereas no serrations occurred at $450^{\circ} \mathrm{C}$ (Figure 2b). The serrated stress amplitude was approximately $30 \mathrm{MPa}$ in the tensile curve at $350^{\circ} \mathrm{C}$, and the critical strain corresponding to the transition from stable to unstable flow is approximately $18.2 \%$.
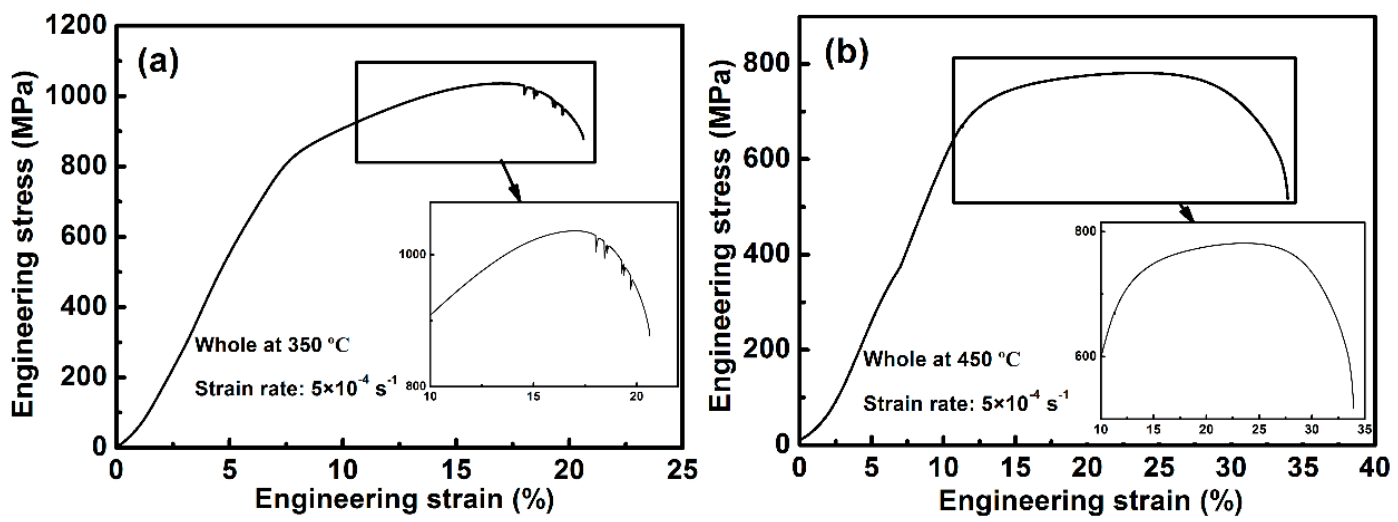

Figure 2. Tensile curve of the whole sample and partial enlarged detail at (a) $350{ }^{\circ} \mathrm{C}$ and (b) $450{ }^{\circ} \mathrm{C}$. 
Because the microstructure of the hot-rolled sheet was not homogenous, as shown in Figure 1, tensile properties of the surface and center part were tested to analyze the origin of the serrated plastic flow. For the surface and center tensile samples, the sampling position corresponds to the rectangular region in Figure 1.

Tensile curves of the center part at $350{ }^{\circ} \mathrm{C}$ and $450{ }^{\circ} \mathrm{C}$ are shown in Figure 3. Serrated flow behavior in tensile curves of the center part at $350{ }^{\circ} \mathrm{C}$ was observed in Figure 3a. The density of serrations was higher than that of the hot-rolled sheet with a thickness of $2.5 \mathrm{~mm}$ (Figure 2a), and the serrated stress amplitude was approximately $15 \mathrm{MPa}$. The serrations started to occur after a certain strain $(20 \%)$, as shown in the curve 1 in Figure 3a. Figure 3a also shows the results for an unloading and re-loading process during tensile test (curves 2 and 3). The tensile stress was unloaded when the serration occurred. After the critical strain for serration, the center samples were loaded again. The serrated flow behavior still occurred in the re-loading process, as shown in the curve 3 in Figure 3 a. At $450{ }^{\circ} \mathrm{C}$, serrations were hardly observed from the tensile curve, as shown in Figure $3 \mathrm{~b}$. For the surface sample, the tensile curve was smooth during deformation at $350{ }^{\circ} \mathrm{C}$, and no serrated flow appeared, as shown in Figure 4.
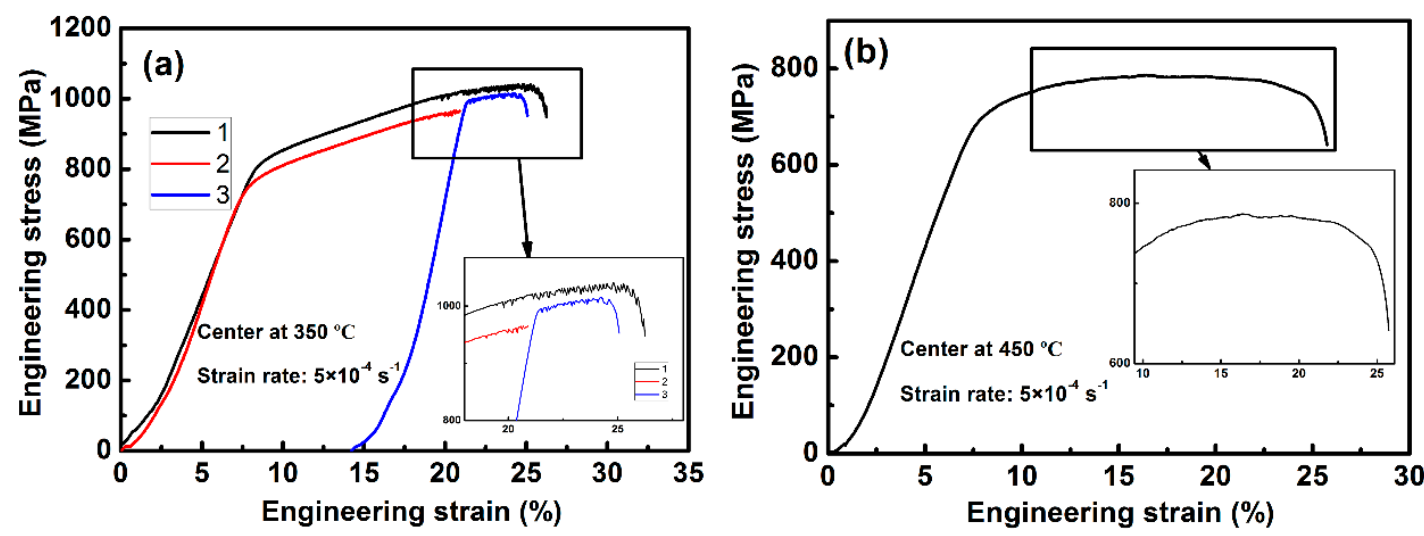

Figure 3. Tensile curves of the center sample at (a) $350{ }^{\circ} \mathrm{C}$ (curve 1: tensile curve; curve 2: loaded curve before the critical strain of the serrated flow; curve 3: reloaded curve) and (b) $450{ }^{\circ} \mathrm{C}$.

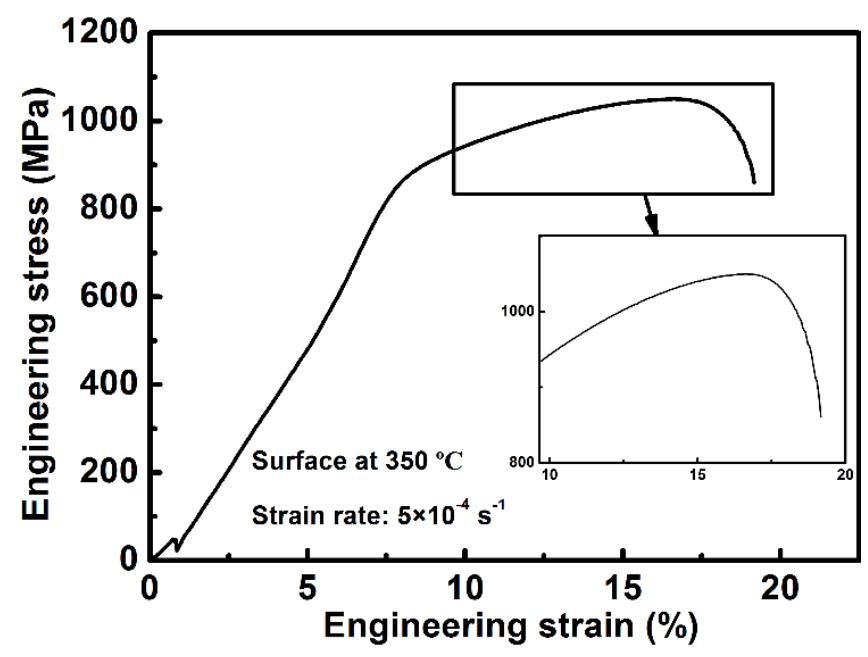

Figure 4. The tensile curve of the surface at $350{ }^{\circ} \mathrm{C}$.

The fracture morphologies after tensile tests are shown in Figure 5. Figure 5a presents the fracture surfaces of the whole sample with a thickness of $2.5 \mathrm{~mm}$ at $350{ }^{\circ} \mathrm{C}$. Different fracture modes are shown in the surface and center part. Ductile dimples were deep in the center part, whereas brittle cleavage fracture occurred in the surface part. A mixture of brittle cleavage and ductile dimple fracture is 
observed in the center in Figure $5 b, c$, and the ductile dimples were deeper at $450{ }^{\circ} \mathrm{C}$ than those at $350^{\circ} \mathrm{C}$. The dimples in Figure $5 \mathrm{~d}$ are somewhat flat, and a brittle cleavage fracture is mainly observed in the fracture surface.
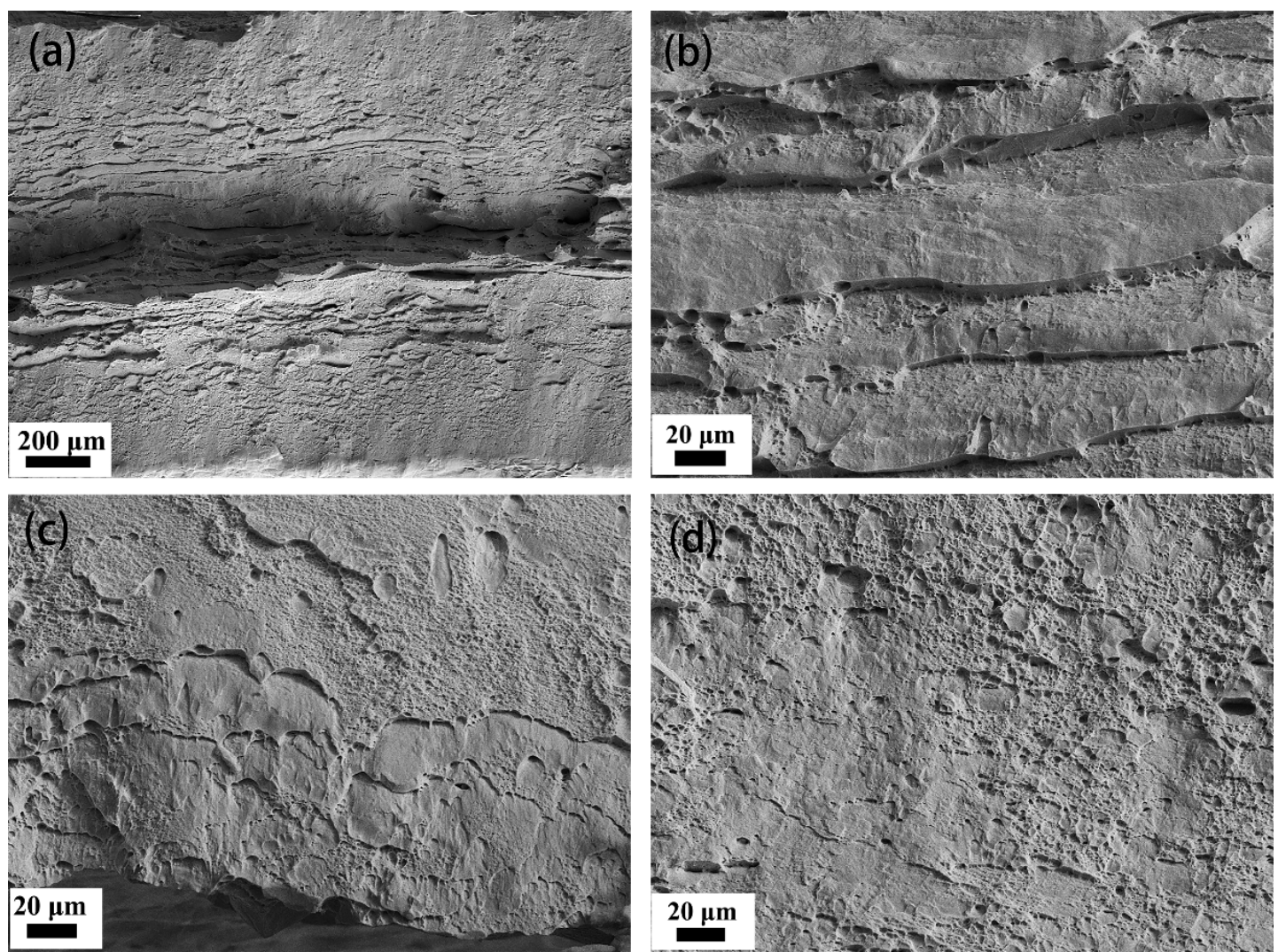

Figure 5. Tensile fracture morphologies of the Fe-6.5wt. $\% \mathrm{Si}$ alloy at $350{ }^{\circ} \mathrm{C}$ and $450{ }^{\circ} \mathrm{C}$. (a) Whole sample at $350{ }^{\circ} \mathrm{C} ;(\mathbf{b})$ center sample at $350{ }^{\circ} \mathrm{C} ;(\mathbf{c})$ center sample at $450{ }^{\circ} \mathrm{C}$; (d) surface sample at $350{ }^{\circ} \mathrm{C}$.

\subsection{Orientation Variation during Warm Deformation}

The crystallographic orientation of the loaded center samples at the critical strain and after tensile fracture (corresponding to curve 2 and curve 1 in Figure 3a) was observed by EBSD, as shown in Figures 6 and 7. Some new orientations emerged during serrated flow deformation (Figure 7), and a slight turn in the grain orientation existed during deformation (Figures 6 and 7). The elongated grains with a strong $<101>$ fiber texture along the rolling direction were observed (Figures $6 \mathrm{~b}$ and $7 \mathrm{~b}$ ). The average misorientation angle between adjacent grains was approximately $8^{\circ}$, and the grain boundaries were straight.
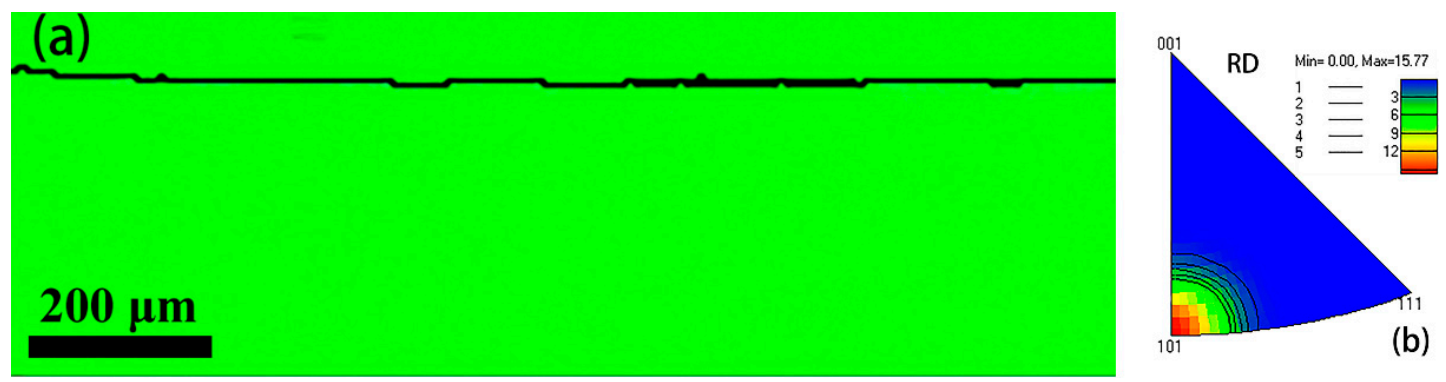

Figure 6. Microstructures of the center samples at the critical strain of the serrated flow behavior. (a) EBSD orientation map at $350^{\circ} \mathrm{C}$; (b) inverse pole figure. 

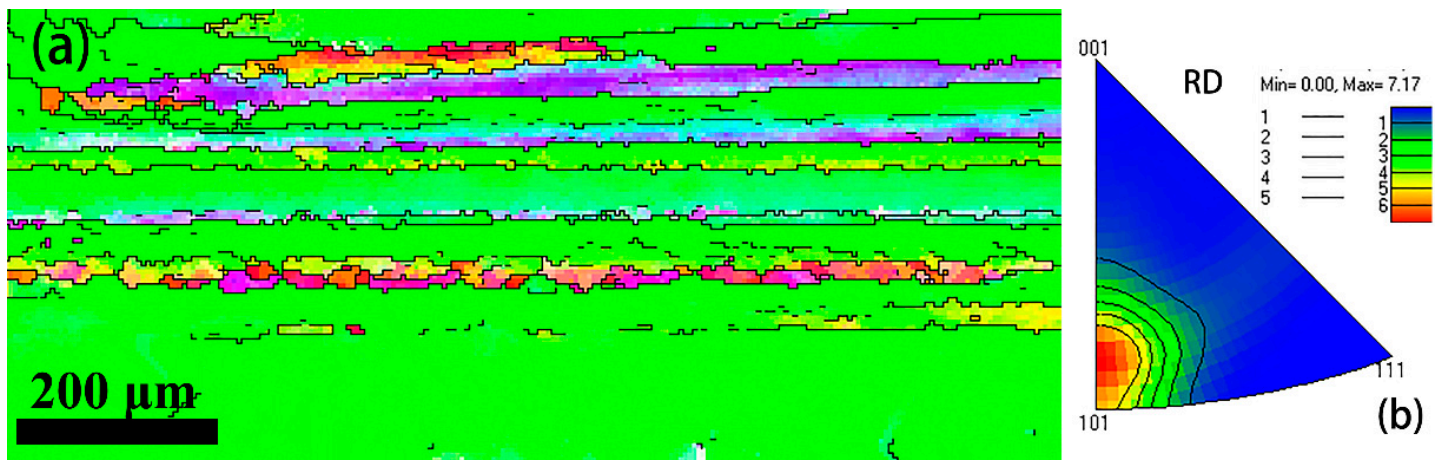

Figure 7. Microstructures of samples after tensile deformation. (a) EBSD orientation map at $350{ }^{\circ} \mathrm{C}$;

(b) inverse pole figure.

\subsection{Variation of Dislocation Configurations during Warm Deformation}

The center samples of the hot-rolled sheet before the tensile test were analyzed by TEM, as shown in Figure 8a. The dislocation density was relatively low, and the dislocation configuration basically exhibited the shape of the network before tensile tests.
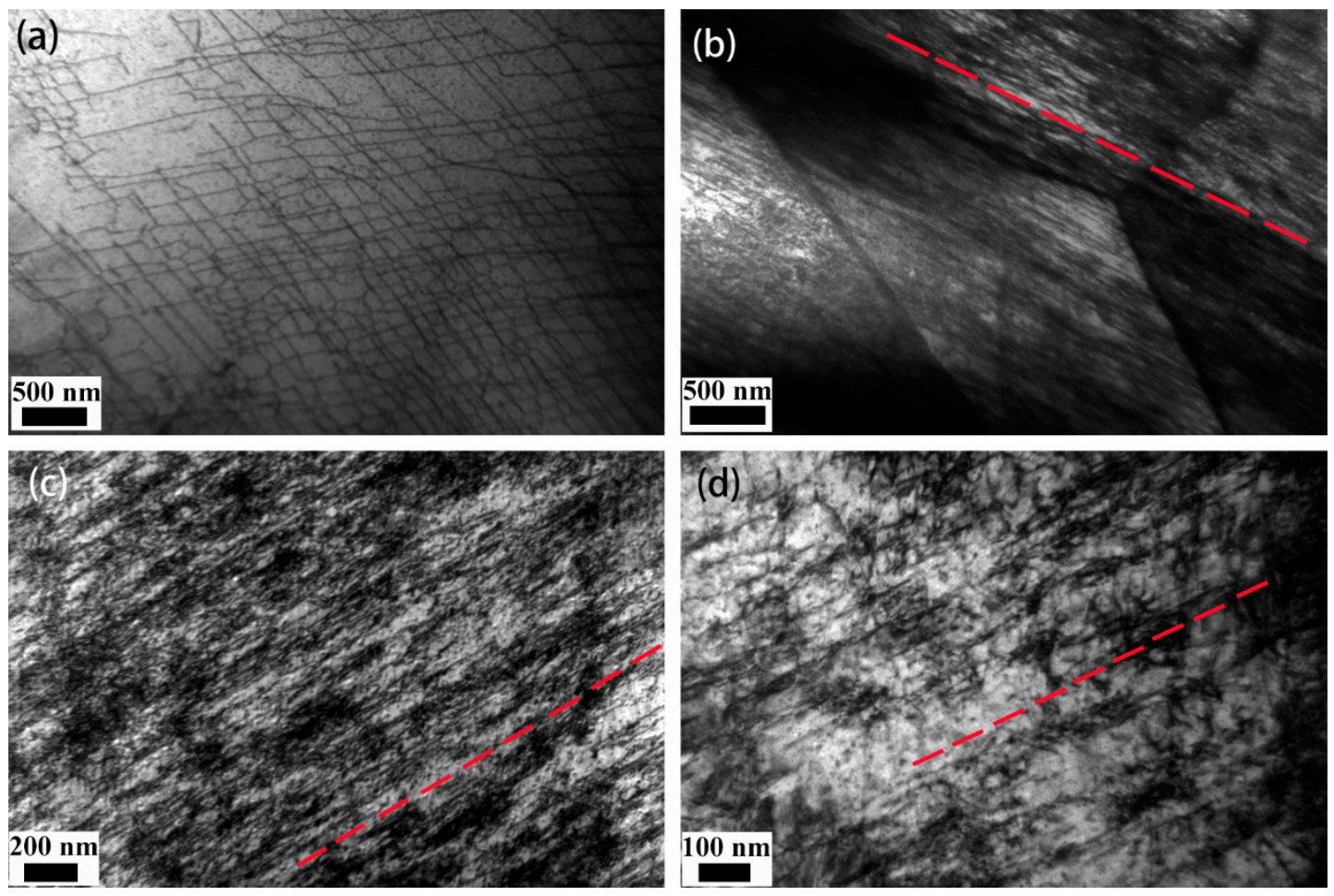

Figure 8. Dislocation configurations in the center samples. (a) Before the tensile tests; (b) the loaded center sample at the critical strain at $350{ }^{\circ} \mathrm{C}$; (c) samples after tensile deformation at $350{ }^{\circ} \mathrm{C}$ in the location with high dislocation density; (d) samples after tensile deformation at $350{ }^{\circ} \mathrm{C}$ in the location with low dislocation density.

Figure $8 \mathrm{~b}$ shows the dislocation configuration of loaded center sample (corresponded to curve 2 in Figure 3a) before the critical strain at $350^{\circ} \mathrm{C}$. The density of dislocations increased compared with that observed in Figure 8a. Dislocations were mostly parallel to each other. Dislocations were not markedly piled up, and some dislocations passed through subgrain boundaries. Figure $8 \mathrm{c}, \mathrm{d}$ show the dislocation configurations of the center samples after tensile tests at $350{ }^{\circ} \mathrm{C}$. A large number of dislocations accumulated, forming approximately parallel forest dislocations. 
During the tensile deformation, the dislocation density gradually increased and dislocations gradually piled up, forming areas of forest dislocations parallel to each other.

\section{Discussion}

\subsection{Cause of the Serrated Flow}

During the tensile tests at $350{ }^{\circ} \mathrm{C}$, serrated flow did not appear in the surface sample (Figure 4), whereas serrated flow was observed in the center sample (Figure 3a). Therefore, the serrated flow of the hot-rolled sheet in Figure 2 is attributed to the serration in the center part.

The serrated flow was considered to be related to the flow units in crystal materials, which are dislocations, plastic-deformation twins, adiabatic shear-softening bands, and even phase-transformation regions [20,21]. Adiabatic shear failure is one of the most important failure modes in metallic materials under impact loading. In terms of force and loading, tensile deformation is different from impact loading. Therefore, the possibility for adiabatic shear can be ruled out. According to the $\mathrm{Fe}$-Si phase diagram [22], below $500{ }^{\circ} \mathrm{C}$, there is no rapid phase transformation in Fe-6.5wt.\%Si alloy. At a low temperature, the critical stress of twins is usually reached first, whereas at an intermediate temperature, dislocations are the flow units [20]. Therefore, the serrated flow behavior can be mainly related to deformation twinning or the interaction of solutes with dislocations.

According to the study of deformation twins of Fe-6.5wt.\%Si alloy by Fu et al. [18,19], deformation twins tended to occur in grains with a tensile orientation near the $<001>$ corner $[18,19]$. However, in this work, the orientation of the center samples was near a $<101>$ orientation $(1,6$, and 7$)$, which is far from a $<100>$ orientation; thus, deformation twins do not easily occur.

In addition, $\mathrm{B} 2$ and $\mathrm{D}_{3}$ ordered phases were observed in the center samples before deformation, as shown in Figure 9. The schematic diagram of the selected area electron diffraction (SAED) patterns can indicate the superlattice diffraction spots of the $\mathrm{B} 2$ and $\mathrm{D0}_{3}$ ordered phases (Figure 9a). The B2 ordered domains are visible in the dark field (DF) image by using the $1 / 2\{200\}$ or $\{111\}$ superlattice reflection (Arrow $\mathrm{A}$ ), and $\mathrm{D}_{3}$ ordered domains are visible by using the $1 / 2\{111\}$ or $1 / 2\{311\}$ superlattice reflection (Arrow B) [22]. The diffraction patterns in Figure $9 \mathrm{~b}$ indicate that there exist $\mathrm{B} 2$ and $\mathrm{DO}_{3}$ ordered phases. It can be seen from Figure $9 c$ that the size range of $B 2$ ordered domain is $200-400 \mathrm{~nm}$. A smoothly curved anti-phase boundary (APB) can be clearly observed. Figure $9 \mathrm{~d}$ is the DF image taken from the $1 / 2\{111\}$ diffraction spot. It is found that the $\mathrm{D}_{3}$ ordered domain is granular.

The degree of order plays an important role in activating deformation twinning in ordered body centered cubic (BCC) alloys. High degree of order in ordered BCC alloys inhibited the formation of deformation twins even under the external conditions favorable to their appearance [23].

A second-order ordering transition (A2-B2) is more reasonably described as an ordered domain growth [24]. It is direct and reliable to characterize the order of degree by ordered domain size. Coarse ordered domain signifies a high degree of ordering. The ordered domain size (200-400 nm) in Figure 9 is much larger than that $(20-200 \mathrm{~nm})$ in the study of deformation twinning by Xie's group $[18,19,25]$. A coarse $\mathrm{B} 2$ ordered structure and granular $\mathrm{D}_{3}$ ordered structure were observed in the center samples (Figure 9), and the degree of order is high. Therefore, the probability of the serrated flow caused by twinning is low.

Furthermore, the results of the EBSD and TEM show that the deformation twins were not found in the center samples after tensile test at $350{ }^{\circ} \mathrm{C}$, and thus the interaction of solutes and dislocations is probably the reason. 
(a)
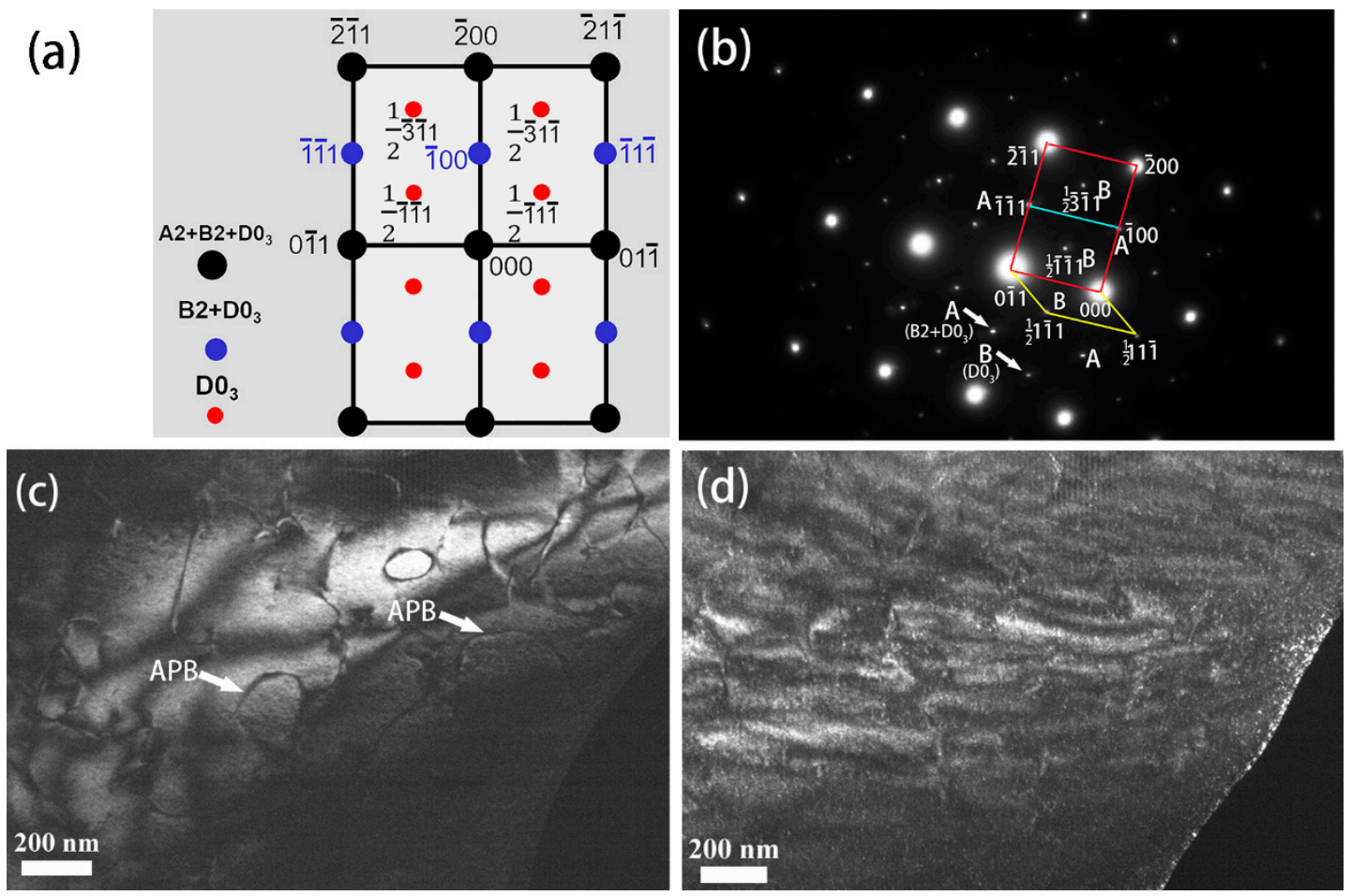

Figure 9. TEM micrographs before deformation along the [011] zone axis. (a) Schematic diagram of the SAED patterns; (b) SAED patterns. Arrow A designates $g=1 / 2\{200\}$ or $\{111\}$ reflection, and arrow B designates $g=1 / 2\{111\}$ or $1 / 2\{311\}$ reflection; (c) DF image by using $1 / 2\{200\}$ diffraction spot; (d) DF image by using $1 / 2\{111\}$ diffraction spot.

\subsection{Mechanism and Evolution of the Serrated Flow}

The serrated plastic flow associated with dislocations is expected to take place, when the velocity of solute diffusion is identical to the velocity of mobile dislocations $[17,26]$. Before the critical strain, dislocations are not piled up. The average speed of dislocation may be higher than the diffusion velocity of solutes atoms. With the increase in strain, on the one hand, the dislocation density increases and dislocations are piled up highly, so that the velocity of mobile dislocations decreases. On the other hand, the increase in dislocation density leads to a large number of vacancies and diffusion channels [27], which further promotes the pipe diffusion and segregation of solute atoms near parallel forest dislocations (Figure 8c,d). At the critical strain in the tensile curve at $350{ }^{\circ} \mathrm{C}$ (Figure 3a), the velocity of solute diffusion is identical to the velocity of mobile dislocations.

According to observation of the dislocation configurations during tensile deformation, forest dislocations parallel to each other are formed in the center samples with the low-angle grain boundary (Figures 7 and 8). The dislocation configurations are similar to those (thick dislocation walls or nearly parallel vein structures indicating localized slip) in single crystals of $\mathrm{Al}_{0.3} \mathrm{CoCrFeNi}$ high-entropy alloy [28] and NiAl alloy [29] in the study of the serrated flow. The slip distance in the dislocation of coarse elongated grains in the center is longer than that of fine equiaxed grains in the surface. The dislocations in the elongated grains tend to be uniform and nearly parallel in slip plane. As a result, serrations take place as a mobile dislocation interacts with these parallel dislocations during deformation.

Combining with previous research [26] and experimental results (Figure 8), the evolution of the serrated flow is shown in Figure 10. Dynamic strain aging is a cooperative process where large groups of dislocations interact. However, in order to facilitate understanding and interpretation, this model of a single dislocation is proposed in this study. The actual dynamic strain aging should be the result of the superposition and mixing of large groups of dislocations based on this model. 


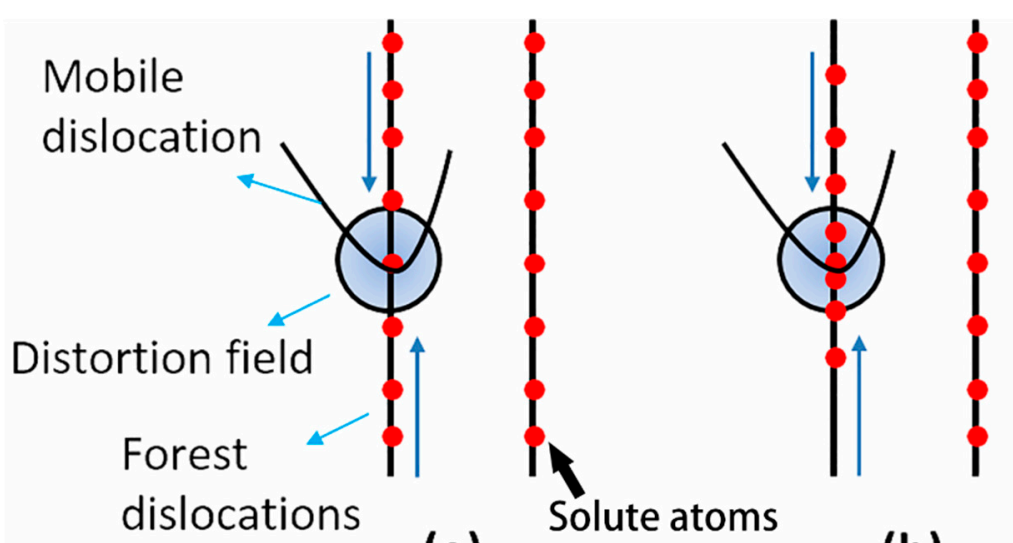

(a) (b)

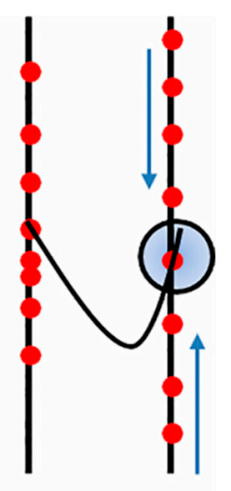

(c)

Figure 10. The evolution of the serrated flow. (a) Mobile dislocations are hindered by forest dislocations; (b) solute atoms (red dots) move along the dislocation line toward the mobile dislocation; (c) mobile dislocations are free from pinning.

First, before the mobile dislocations are blocked, solute atoms have been segregated around parallel forest dislocations (Figure 10a). Second, when the mobile dislocations are blocked by forest dislocations, solute atoms around the forest dislocations move along the core of the dislocation toward the mobile dislocation to create additional pinning, and then the solute motion in the distortion field causes some strengthening in the intersection points between mobile and forest dislocations (Figure 10a,b). As the deformation continues, the stress increases (intersection strengthening). Finally, the mobile dislocations are free from pinning due to the increasing stress, and there is an instantaneous increase in the mobile dislocation density (Figure 10c). The stress begins to relax [27]. As the mobile dislocations continue to move forward, they are hindered by the next forest dislocation (Figure 10c).

\section{Conclusions}

The microstructures and tensile deformation behavior of hot-rolled Fe-6.5wt.\%Si alloy were investigated.

(1) The hot-rolled Fe-6.5\%Si sheet exhibits a layered structure along the thickness direction. The surface part is composed of equiaxed grains, whereas the center part shows elongated grains with a $<101>$ fiber texture parallel to the rolling direction.

(2) Serrated flow behavior occurs in both the hot-rolled sheet and its center region sample at $350{ }^{\circ} \mathrm{C}$, whereas serrated flow does not appear in the surface sample. Therefore, the serrated flow of the hot-rolled sheet is attributed to the serration in the center sample.

(3) Based on analyses of the degree of order, grain orientation, and dislocation configurations, it can be deduced that the serrated flow behavior may be caused by the interaction of solutes and mobile dislocations. This model of dynamic strain aging is proposed, and the serrated flow behavior is the result of the superposition and mixing of large groups of dislocations based on this model.

Author Contributions: X.S. conceived, designed and performed the experiments; B.Z. contributed to the EBSD work; B.L. contributed to ideas and intensive discussions. X.S. wrote the manuscript; F.Y., Y.L. and Z.D. supervised the work.

Funding: This research was funded by National Natural Science Foundation of China (51471031, U1660115), Program of Introducing Talents of Discipline to Universities (B07003), and the State Key Laboratory for Advanced Metals and Materials (2016Z-17).

Acknowledgments: Financial supports from the National Natural Science Foundation of China (51471031, U1660115), the State Key Laboratory for Advanced Metals and Materials (2016Z-17), and the Program of Introducing Talents of Discipline to Universities (No. B07003) are gratefully acknowledged.

Conflicts of Interest: The authors declare no conflict of interest. 


\section{References}

1. Ouyang, G.; Chen, X.; Liang, Y.; Macziewski, C.; Cui, J. Review of Fe-6.5 wt\% Si high silicon steel-A promising soft magnetic material for sub-kHz application. J. Magn. Magn. Mater. 2019, 481, $234-250$. [CrossRef]

2. Phway, T.P.P.; Moses, A.J. Magnetostriction trend of non-oriented 6.5\% Si-Fe. J. Magn. Magn. Mater. 2008, 320, e611-e613. [CrossRef]

3. Raviprasad, K.; Tenwick, M.; Davies, H.A.; Chattopadhyay, K. The nature of ordered structures in melt spun iron-silicon alloys. Scr. Metall. 1986, 20, 1265-1270. [CrossRef]

4. Matsumura, S.; Oyama, H.; Oki, K. Dynamical behavior of ordering with phase separation in off-stoichiometric Fe3Si alloys. Mater. Trans. JIM 1989, 30, 695-706. [CrossRef]

5. Matsumura, S.; Tanaka, Y.; Koga, Y.; Oki, K. Concurrent ordering and phase separation in the vicinity of the metastable critical point of order-disorder transition in Fe-Si alloys. Mater. Sci. Eng. A 2001, 312, $284-292$. [CrossRef]

6. $\quad$ Liang, Y.F.; Ye, F.; Lin, J.P.; Wang, Y.L.; Chen, G.L. Effect of annealing temperature on magnetic properties of cold rolled high silicon steel thin sheet. J. Alloys Compd. 2010, 491, 268-270. [CrossRef]

7. Li, H.; Liang, Y.F.; Yang, W.; Ye, F.; Lin, J.P.; Xie, J.X. Disordering induced work softening of Fe-6.5wt $\% S i$ alloy during warm deformation. Mater. Sci. Eng. A 2015, 628, 262-268. [CrossRef]

8. Fu, S.; Cheng, T.; Zhang, Q.; Hu, Q.; Cao, P. Two mechanisms for the normal and inverse behaviors of the critical strain for the Portevin-Le Chatelier effect. Acta Mater. 2012, 60, 6650-6656. [CrossRef]

9. Cai, Y.L.; Yang, S.L.; Wang, Y.H.; Fu, S.H.; Zhang, Q.C. Characterization of the deformation behaviors associated with the serrated flow of a 5456 Al-based alloy using two orthogonal digital image correlation systems. Mater. Sci. Eng. A 2016, 664, 155-164. [CrossRef]

10. Min, J.; Hector Jr, L.G.; Zhang, L.; Sun, L.; Carsley, J.E.; Lin, J. Plastic instability at elevated temperatures in a TRIP-assisted steel. Mater. Des. 2016, 95, 370-386. [CrossRef]

11. Sun, B.A.; Liu, C.T.; Yang, Y. Rate dependence of serrated flow and its effect on shear stability of bulk metallic glasses. J. Iron. Steel Res. Int. 2016, 23, 24-30. [CrossRef]

12. Wang, W.H.; Wu, D.; Shah, S.S.A.; Chen, R.S.; Lou, C.S. The mechanism of critical strain and serration type of the serrated flow in Mg-Nd-Zn alloy. Mater. Sci. Eng. A 2016, 649, 214-221. [CrossRef]

13. Xu, Z.; Shen, Y. Serrated flow and work-hardening behavior of China low activation martensitic steel (CLAM). Metals 2018, 8, 413. [CrossRef]

14. Wen, S.; Xue, S.; Han, C.; Liu, B.; Liang, Y.; Ye, F. Fabrication technology and material characterization of hot rolled cylindrical Fe-6.5 wt.\% Si bars. Metals 2018, 8, 371. [CrossRef]

15. Honjo, H.; Kaneno, Y.; Inoue, H.; Takasugi, T. Plastic flow instabilities of $\mathrm{L}_{2} \mathrm{Ni}_{3} \mathrm{Al}$ alloys at intermediate temperatures. J. Mater. Sci. 2004, 39, 3677-3681. [CrossRef]

16. Honjo, H.; Kaneno, Y.; Inoue, H.; Takasugi, T. Plastic flow instabilities of $\mathrm{L}_{2} \mathrm{Ni}_{3}$ (Si, Ti) alloys at intermediate temperature. J. Mater. Res. 2002, 17, 705-711. [CrossRef]

17. Takasugi, T.; Honjo, H.; Kaneno, Y.; Inoue, H. Plastic flow instabilities of $\mathrm{Ll}_{2} \mathrm{Co}_{3} \mathrm{Ti}$ alloys at intermediate temperatures. Acta Mater. 2002, 50, 847-855. [CrossRef]

18. Fu, H.; Zhang, Z.; Jiang, Y.; Xie, J. Applying the grain orientation dependence of deformation twinning to improve the deformation properties of an Fe-6.5wt\%Si alloy. J. Alloys Compd. 2016, 689, 307-312. [CrossRef]

19. Xie, J.; Fu, H.; Zhang, Z.; Jiang, Y. Deformation twinning feature and its effects on significant enhancement of tensile ductility in columnar-grained Fe-6.5wt.\%Si alloy at intermediate temperatures. Intermetallics 2012, 23, 20-26. [CrossRef]

20. Zhang, Y.; Qiao, J.W.; Liaw, P.K. A brief review of high entropy alloys and serration behavior and flow units. J. Iron. Steel Res. Int. 2016, 23, 2-6. [CrossRef]

21. Zhang, Y.; Liu, J.P.; Chen, S.Y.; Xie, X.; Liaw, P.K.; Dahmen, K.A.; Wang, Y.L. Serration and noise behaviors in materials. Prog. Mater. Sci. 2017, 90, 358-460. [CrossRef]

22. Li, H.; Liang, Y.F.; Ye, F. Effect of heat treatment on ordered structures and mechanical properties of Fe-6.5mass\%Si Alloy. Mater. Trans. 2015, 56, 759-765. [CrossRef]

23. Cahn, R.W. Twinning in iron-aluminium alloys. Acta Metall. 1961, 9, 138-148. [CrossRef] 
24. Cui, S.; Ouyang, G.; Ma, T.; Macziewski, C.R.; Levitas, V.I.; Zhou, L.; Kramer, M.J.; Cui, J. Thermodynamic and kinetic analysis of the melt spinning process of Fe-6.5wt.\%Si alloy. J. Alloys Compd. 2019, 771, 643-648. [CrossRef]

25. Zhang, Z.; Wang, W.; Fu, H.; Xie, J. Effect of quench cooling rate on residual stress, microstructure and mechanical property of an Fe-6.5Si alloy. Mater. Sci. Eng. A 2011, 530, 519-524. [CrossRef]

26. Klose, F.B.; Ziegenbein, A.; Weidenmüller, J.; Neuhäuser, H.; Hähner, P. Portevin-LeChatelier effect in strain and stress controlled tensile tests. Comput. Mater. Sci. 2003, 26, 80-86. [CrossRef]

27. Rodriguez, P. Serrated plastic flow. Bull. Mater. Sci. 1984, 6, 653-663. [CrossRef]

28. Yasuda, H.Y.; Shigeno, K.; Nagase, T. Dynamic strain aging of $\mathrm{Al}_{0.3} \mathrm{CoCrFeNi}$ high entropy alloy single crystals. Scr. Mater. 2015, 108, 80-83. [CrossRef]

29. Weaver, M.L.; Kaufman, M.J.; Noebe, R.D. Manifestations of dynamic strain aging in soft-oriented NiAl single crystals. Metall. Mater. Trans. A 1996, 27, 3542-3557. [CrossRef]

(C) 2019 by the authors. Licensee MDPI, Basel, Switzerland. This article is an open access article distributed under the terms and conditions of the Creative Commons Attribution (CC BY) license (http://creativecommons.org/licenses/by/4.0/). 